\title{
Within and Beyond the Nucleotide Addition Cycle of Viral RNA-dependent RNA Polymerases
}

\author{
Peng Gong ${ }^{1,2 *}$ \\ ${ }^{1}$ Key Laboratory of Special Pathogens and Biosafety, Wuhan Institute of Virology, Center for Biosafety Mega-Science, Chinese \\ Academy of Sciences, Wuhan, China, ${ }^{2}$ Drug Discovery Center for Infectious Diseases, Nankai University, Tianjin, China
}

Nucleotide addition cycle (NAC) is a fundamental process utilized by nucleic acid polymerases when carrying out nucleic acid biosynthesis. An induced-fit mechanism is usually taken by these polymerases upon NTP/dNTP substrate binding, leading to active site closure and formation of a phosphodiester bond. In viral RNA-dependent RNA polymerases, the post-chemistry translocation is stringently controlled by a structurally conserved motif, resulting in asymmetric movement of the template-product duplex. This perspective focuses on viral RdRP NAC and related mechanisms that have not been structurally clarified to date. Firstly, RdRP movement along the template strand in the absence of catalytic events may be relevant to catalytic complex dissociation or

OPEN ACCESS

Edited by:

Whitney Yin,

University of Texas Medical Branch at Galveston, United States

Reviewed by: David Douglas Boehr, The Pennsylvania State University (PSU), United States Georgiy Belogurov, University of Turku, Finland

*Correspondence: Peng Gong gongpeng@wh.iov.cn

Specialty section: This article was submitted to

Structural Biology, a section of the journal Frontiers in Molecular Biosciences

Received: 25 November 2021 Accepted: 21 December 2021 Published: 10 January 2022

Citation:

Gong P (2022) Within and Beyond the Nucleotide Addition Cycle of Viral RNAdependent RNA Polymerases. Front. Mol. Biosci. 8:822218. doi: 10.3389/fmolb.2021.822218 proofreading. Secondly, pyrophosphate or non-cognate NTP-mediated cleavage of the product strand $3^{\prime}$-nucleotide can also play a role in reactivating paused or arrested catalytic complexes. Furthermore, non-cognate NTP substrates, including NTP analog inhibitors, can not only alter NAC when being misincorporated, but also impact on subsequent NACs. Complications and challenges related to these topics are also discussed.

Keywords: RNA virus, RNA-dependent RNA polymerase, nucleotide addition cycle, translocation, cleavage, misincorporation, nucleotide analog

\section{INTRODUCTION}

RNA viruses are a large collection of diverse, rapidly evolving viruses with a wide host range covering bacteria and eukaryotes (Krupovic et al., 2018). In recent years, emerging and re-remerging RNA viruses causing human and animal diseases have posed a great impact to our daily life. Understanding the fundamental features of RNA viruses has become an attractive and rapid growing research area ever since the emergence of severe and acute syndrome coronavirus 2 (SARS-CoV-2) causing the coronavirus disease 2019 (COVID-19) (Zhou et al., 2020). Effective antivirals and vaccines are in urgent need for prevention and control of known and future RNA virus pathogens. One unique feature of RNA viruses is that their genome replication and transcription processes are DNA-independent, thus requiring a virally-encoded RNA-dependent RNA polymerase (RdRP) to carry out these essential processes of the virus life cycle (Wolf et al., 2018). Due to their essentialness and highest conservation level, RdRPs have become attractive targets to develop antivirals with high potency and/or broad-spectrum potential. Although being considered the most conserved protein of RNA viruses, RdRPs are still quite diverse with respect to their global structure organization (Lesburg et al., 1999; Thompson and Peersen, 2004; Lu and Gong, 2013; Pflug et al., 2014; Liang et al., 2015; Jia and Gong, 2019; Kirchdoerfer and Ward, 2019), initiation mechanisms 


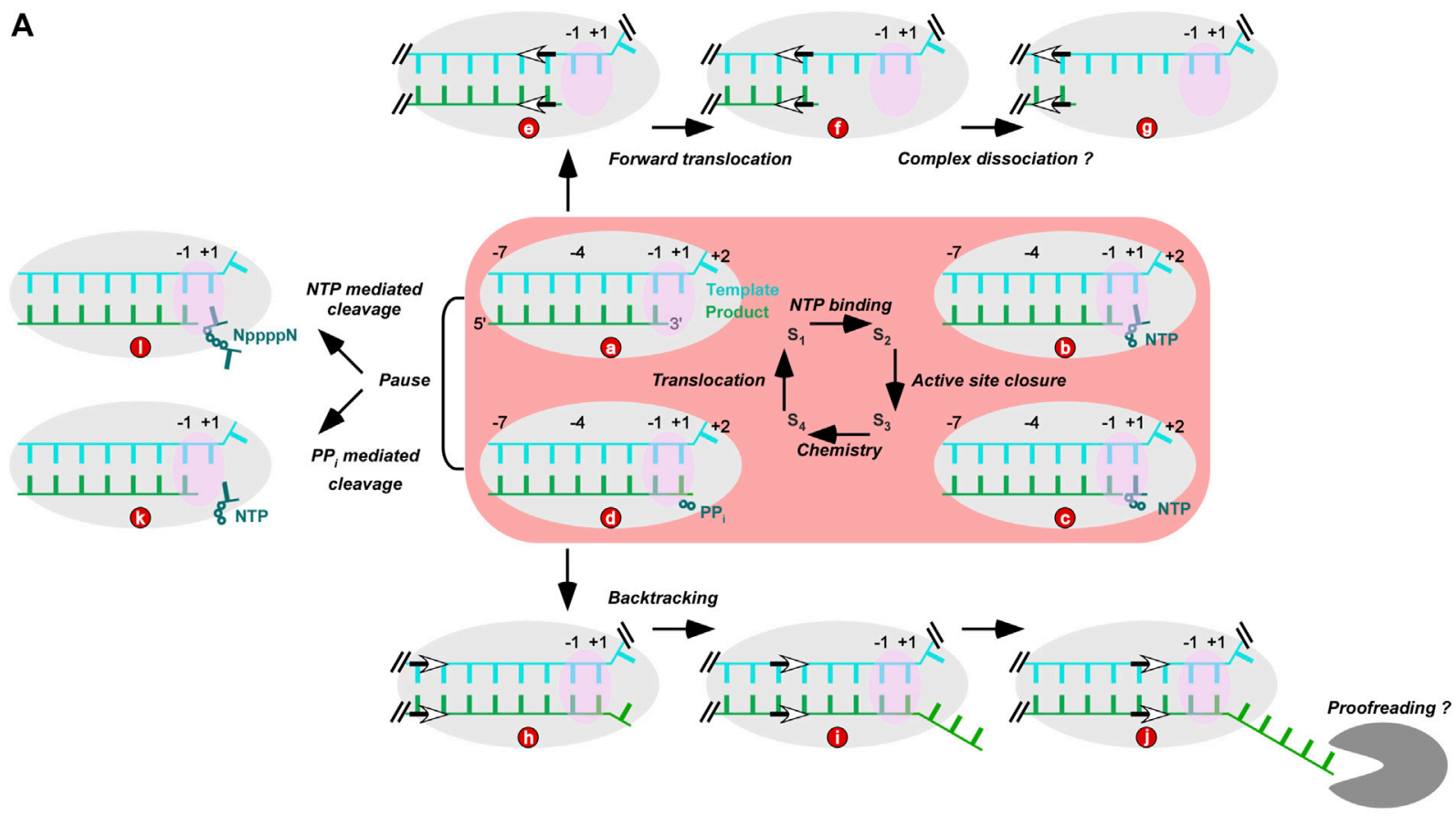

B

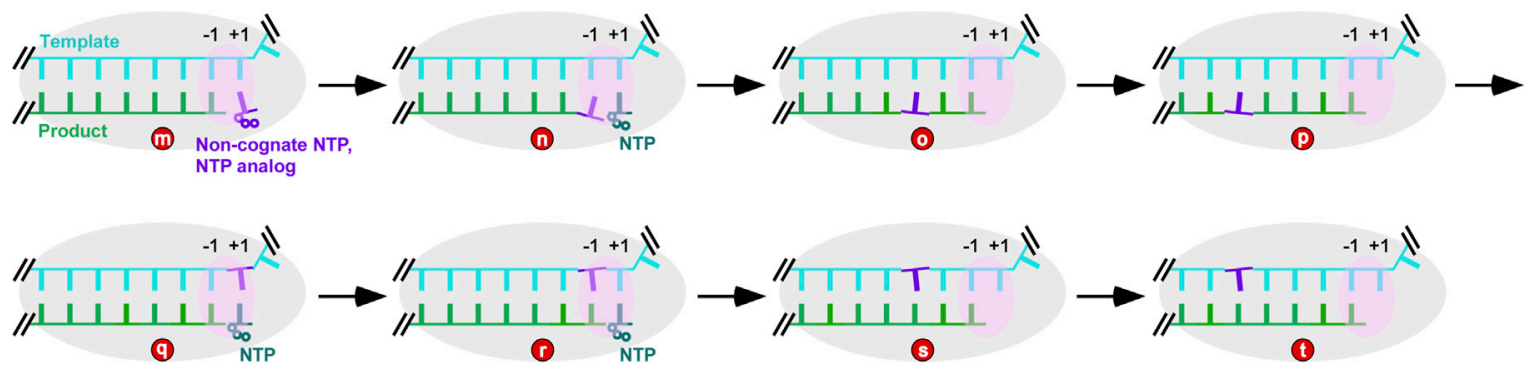

FIGURE 1 | Viral RdRP NAC and possibly related processes. (A) RdRP NAC and its relationship with nucleotide addition-free translocation events and intrinsic product cleavage activities. (a-d): four reference states of NAC; e-g: states derived from RdRP forward translocation; (h-j): states derived from polymerase backtracking; d to k: PP mediated product cleavage; $d$ to I: non-cognate NTP-mediated cleavage. The gray "pacman" represents a virally encoded exonuclease. (B) NAC intervention by incorporation of non-cognate NTP or NTP analogs. Gray and pink ovals represent RdRP and its active site, respectively. Wherever necessary, double slashes were used to indicate continuation of an RNA strand.

(Butcher et al., 2001; Reich et al., 2014; Appleby et al., 2015; Zhang et al., 2021), and regulation by host and viral factors (Kidmose et al., 2010; Liu et al., 2018; Chen et al., 2020; Yan et al., 2021a). Nucleotide addition cycle (NAC), a process shared by all nucleic acid polymerases carrying out NTP/dNTP-driven phosphodiester bond formation (Huang et al., 1998; Li et al., 1998; Yin and Steitz, 2004; Kornberg, 2007; Gong and Peersen, 2010), may thus be the most conservative part of viral RdRP working mechanisms. Understandings of common features in RdRP NAC can help describe the viral genome replication and transcription processes that are composed of thousands of NACs and can benefit development of nucleot(s)ide analog drugs targeting viral RdRPs (Gong, 2021; Johnson and Dangerfield, 2021).

NAC of nucleic acid polymerase typically contain four microsteps: NTP/dNTP binding, active site closure, phosphoryl transfer reaction (chemistry), and translocation, while four structural reference states $\left(\mathrm{S}_{1}-\mathrm{S}_{4}\right)$ are usually used to help depict these microsteps (Figure 1A, central part with pink background). Critical conformational changes have been found accompanying active site closure $\left(\mathrm{S}_{2}\right.$ to $\left.\mathrm{S}_{3}\right)$ and translocation $\left(\mathrm{S}_{4}\right.$ to $S_{1}$ ) (Temiakov et al., 2004; Yin and Steitz, 2004; Wang et al., 2006). In viral RdRPs, a unique palm-domain-based conformational change takes place upon active site closure (Zamyatkin et al., 2008; Gong and Peersen, 2010; Appleby et al., 2015). By contrast, A-family polymerases represented by bacteriophage T7 RNA polymerase and Thermus aquaticus (Taq) DNA polymerase close the active site through a large-scale conformational change of their fingers domain (Li et al., 1998; Yin and Steitz, 2004). $S_{3}$ and $S_{4}$ structures that both have a closed active site have been solved in multiple polymerase systems, and consistently demonstrate the critical role of two divalent metal 
ions in forming the transition state of the phosphoryl transfer reaction (Steitz and Steitz, 1993). Two types of RdRP translocation intermediate structures both highlight an asymmetric movement of the template-product RNA strands and stringent control of the template RNA movement by the RdRP-specific template-interacting motif G (Shu and Gong, 2016; Wang et al., 2020a). Similar intermediates have been observed with transcriptional pausing-related multi-subunit DNA-dependent RNA polymerases (DdRPs) (Guo et al., 2018; Kang et al., 2018), suggesting that this phenomenon may be shared even by structurally unrelated polymerase families.

Although numerous NAC-state-related structures from various viral RdRPs have provided a relatively complete structural view of the cognate NTP-driven NAC, several aspects directly or indirectly related to NAC have rarely been addressed structurally in RdRPs including nucleotide additionfree translocation, intrinsic product cleavage activities, and perturbation of NAC by non-cognate NTPs and NTP analogs. As discussed below, these events are possibly related to important events including but not limited to RdRP catalytic complex dissociation, proofreading, reactivation, fidelity control, and effective intervention. In the following sections, a synoptic introduction of these events and structural challenges to approach them are discussed.

\section{RDRP TRANSLOCATION BEYOND NAC}

$S_{1}$ and $S_{4}$ represent the post- and pre-translocation states, respectively. In a classic NAC, a post-translocation $S_{1}$ complex directs the binding of the incoming NTP, while the polymerase in the pre-translocation $\mathrm{S}_{4}$ complex needs to translocate to the next register and reopen its active site for the next NAC (Figure 1A, central panel with pink background). By contrast, "forward" movement from the post-translocation $S_{1}$ and "backward" movement from the pre-translocation $\mathrm{S}_{4}$ of the polymerase can move the polymerase out of an NAC. The former, if occurs successively, makes the $3^{\prime}$-end of the product RNA move toward the upstream. The template-product duplex in contact with the polymerase thus shortens and may lead to dissociation of the complex (Figure 1Aa,e-g). These forwardtranslocated states occur in DdRPs during intrinsic transcription termination or in halted transcription elongation complexes, both resulting in dissociation of the polymerase complex (Yarnell and Roberts, 1999; Zhou et al., 2007). Similar situations may also be induced by other nucleic acid binding proteins or nucleic acid elements such as bacterial translocase Rho, bacterial transcription-repair coupling factor $\mathrm{Mfd}$, or the class I transcription termination signal in T7 RNA polymerase transcription (Kassavetis and Chamberlin, 1981; Macdonald et al., 1994; Deaconescu et al., 2006; Murphy et al., 2009; Roberts, 2019). However, dissociation routes unrelated to RdRP forward translocation cannot be ruled out. Furthermore, a Brownian ratchet model applied to DdRPs suggests that polymerase can slide along the nucleic acid template driven by thermal motion with the binding of incoming NTP serving as the "ratchet" to favor the forward-translocated state (Guajardo and
Sousa, 1997; Vassylyev and Artsimovitch, 2005). Therefore, RdRP may forward translocate simply through "diffusing" along the template even without cis-acting elements or trans-acting factors.

The "backward" movement of the polymerase, better known as backtracking in DdRP transcription, results in unraveling of the template-product duplex downstream of the +1 site (the position where incoming NTP binds during NAC). In DdRPs, there is a channel to accommodate the single-stranded $3^{\prime}$-portion of the product RNA and transcription factors such as bacterial GreA/GreB and eukaryotic TFIIS can facilitate intrinsic endonuclease activity of DdRP to reactivate transcription (Abdelkareem et al., 2019; Bradley et al., 2019; Wang et al., 2009). Proofreading activities in viral RdRPs have been found in CoVs, with the virally encoded nsp14 protein utilizing its exonuclease module to excise the $3^{\prime}$-nucleotide(s) of the product RNA (Subissi et al., 2014) (Figure 1Ad,h-j). Backtracking-related proofreading models were proposed in SARS-CoV-2 RdRP studies, in which the viral helicase hypothetically facilitates RdRP backtracking upon misincorporation and the $3^{\prime}$-end of the product therefore is delivered to the exonuclease active site for cleavage after multiple rounds of translocation events (Chen et al., 2020; Yan et al., 2021b).

Except for recently reported backtracked SARS-CoV-2 RdRP structures obtained using RNA scaffolds with designed mismatches at the $3^{\prime}$-portion of the product RNA (Malone et al., 2021), structures with the $3^{\prime}$-end of the product strand poise upstream of position -1 (the position of the priming nucleotide of the product strand) or downstream of position +1 have rarely been captured in viral RdRPs. Nevertheless, these nucleotide-addition-free translocation events likely occurs and may indeed play important roles under certain circumstances. On one hand, assembling an RdRP-RNA complex with other factors may help visualize the forward translocated or backtracked states. On the other hand, RdRP variants (i.e., from different viruses or virus strains) or mutants with altered nature in controlling the movement of either the template or the product strand may have different odds in capturing these states by structural biology approaches.

\section{RDRP INTRINSIC CLEAVAGE ACTIVITIES AND THEIR RELEVANCE TO REACTIVATION}

Pyrophosphate $\left(\mathrm{PP}_{\mathrm{i}}\right)$ is the byproduct of the NTP/dNTP-driven phosphoryl transfer reaction in NAC. Under certain circumstances (e.g., high $\mathrm{PP}_{\mathrm{i}}$ concentration in polymerase assays), $\quad \mathrm{PP}_{\mathrm{i}}$ can reverse the reaction through pyrophosphorolysis (Figure 1Ac,d-k). Pyrophosphorolysis can not only participate in proofreading by excising the non-cognate nucleotide, but also play regulatory roles by modulating the overall progress of nucleic acid synthesis (Imashimizu et al., 2019). While $\mathrm{PP}_{\mathrm{i}}$ can be observed in pre-translocation polymerase complex structures (Yin and Steitz, 2004; Gong and Peersen, 2010), it has not been observed in polymerase structures that has completed translocation, suggesting that $\mathrm{PP}_{\mathrm{i}}$ release and translocation likely coincide in timing. Starting 
from a post-translocation $S_{1}$ complex crystal, an interesting reverse translocation intermediate structure was captured in an enterovirus RdRP with $\mathrm{PP}_{\mathrm{i}}$ present in the soaking solution (Wang et al., 2020a). In such a structure, the $3^{\prime}$-nucleotide of the product moved from position -1 to almost position +1 . Although pyrophosphorolysis did not occur in the crystal, solution trials mimicking the crystal soaking condition led to observation of $\mathrm{PP}_{\mathrm{i}}$-mediated cleavage (Wang et al., 2020a) (Figure 1Ad-k), suggesting reverse translocation as a prerequisite of the cleavage of a post-translocation complex. Another interesting observation in this structure is the "slippage" between the template-product RNA, resulting in a duplex only partially matched. Completion of this reverse translocation thus requires realigning of the two strands. Such a slippage-andrealigning process was not observed in regular forward translocation, in which basepairing interactions between the two strands were maintained (Shu and Gong, 2016; Peersen, 2017; Wang et al., 2020a). Hence, the reverse translocation is relatively energetically-unfavorable.

Another known polymerase activity cleaving the $3^{\prime}$-nucleotide of the product strand is mediated by non-cognate NTPs. First reported in human immunodeficiency virus 1 (HIV-1) reverse transcriptase (RT), a non-cognate NTP can induce the cleavage of the product strand $3^{\prime}$-nucleotide, forming a dinucleotide with a 5-5' poly-phosphate (tetra- or tri-phosphate) linkage when the incoming cognate dNTP is not available (Meyer et al., 1998). Similar activities were subsequently observed in hepatitis $C$ virus (HCV) RdRP (Jin et al., 2013a). In both systems, a chain terminating nucleotide can be cleaved by this NTP-mediated activity to yield an extendable $3^{\prime}$-end, and thus implying its potential role in proofreading.

Unlike CoVs, many other RNA viruses do not encode an exonulease and thus sometimes are considered error-prone. However, $\mathrm{PP}_{\mathrm{i}^{-}}$and NTP-mediated cleavage activities by RdRP itself may play key roles in maintaining viral genome stability and keeping the virus away from the error-catastrophe threshold (Crotty et al., 2001). Furthermore, RdRP pausing or arrest caused by RNA elements or regulatory proteins can in principle also be resolved by these activities. As polymerases can pause at either pre- or post-translocation NAC states (Figures 1Aa,d) but both cleavage activities likely occur at pre-translocation state (Figure 1Ad-l), polymerase backtracking to the pre-translocational position for cleavage may increase the opportunity of rescuing the complex from a "trapped" status. To date, the structural basis of the NTPmediated cleavage has remained elusive, while structural understandings of pyrophosphorolysis can be readily achieved through its reverse steps of nucleotide addition and the preceding reverse translocation.

\section{RDRP NAC REGULATION BY NON-COGNATE NTP OR NTP ANALOGS}

As the major source of nucleotide mutations, misincorporation by nucleic acid polymerases and its mechanisms are of great interest in understanding evolution of species.
Misincorporations, often considering basepairing mismatch derived events, occur at a rate of $10^{-3}-10^{-5}$ if not considering proofreading (Drake and Holland, 1999; Chen et al., 2000; Johnson et al., 2000; Zhang et al., 2000). Therefore, it is generally difficult to capture misincorporation-related polymerase structural states. A classic work in this aspect is from a systematic study in Bacillus stearothermophilus DNA polymerase I fragment (BF), a high-fidelity DNA polymerase (Johnson and Beese, 2004). By attempting every possible mismatched base pair combination, multiple mismatchcontaining crystal structures were solved at atomic resolution, depicting various types of mismatches and their direct impact on NAC. By solving a set of structures with extension of a G:T mismatch in successive NACs, distortion of a mismatch up to six register from the $3^{\prime}$-end of the product was found to have an impact on the active site through long-range transmission. By contrast, systematic structure determination of mismatchcontaining RdRP catalytic complexes is lacking.

The successful usage (Rubin et al., 2020) of nucleotide/ nucleoside analog (NA) drugs in treating RNA virus related disease have emphasized the importance of this class of compounds in prevention and control of existing and future pathogens (Furuta et al., 2013; Gane et al., 2013; Rubin et al., 2020). However, multiple factors including but not limited to the differences among RdRP active sites, differences in optimal prodrug forms targeting certain cell types, and emergence of drug-resistant virus strains determine the effectiveness of an NA on a certain virus and its broad-spectrum potential (Feng and Ray, 2021; Jia et al., 2021; Seley-Radtke et al., 2021). Understanding the intervention mechanism of the NTP form of NA (the effective molecule in vivo) at enzymology and structural levels is a key not only to identify repurposed NA drugs, but also to design new NA drugs (Appleby et al., 2015; Xu et al., 2017). As an example, remdesivir (RDV), a ribose $1^{\prime}$ substituted adenosine analog, was first developed for Ebola treatment and was found effective on other viruses including various CoVs (Cho et al., 2012; Jacobs et al., 2016; Agostini et al., 2018; Gordon et al., 2020a). A delayed intervention by the NTP form of RDV (RDV-TP) likely at the third NAC after the first incorporation was found in CoVs and subsequently in enterovirus 71 (EV71) (Gordon et al., 2020b; Wu et al., 2021), demonstrating both uniqueness and diversity of this compound in RdRP intervention. Further characterizations revealed that structurally equivalent S861 and S417 in SARS-CoV-2 and EV71 RdRPs are responsible for this delayed intervention likely through steric hindrance of the RDV $1^{\prime}$-cyano group, and under certain circumstances the incorporated RDV (i.e., the monophosphate form of RDV) can overcome this serine roadblock (Tchesnokov et al., 2020; Kokic et al., 2021; Seifert et al., 2021; Wu et al., 2021). The non-terminating feature of RDV intervention awaits further investigation considering the entire replication/transcription process as well as viral protein translation if RDV-containing transcripts are utilized to direct protein synthesis. The $1^{\prime}$ substitutions are therefore endowed with broad-spectrum and delayed intervention potentials in NA drug development. Another notable NA type is represented by ribavirin, favipiravir, and molnupiravir, all with ambiguous basepairing 
capability (Crotty et al., 2000; Jin et al., 2013b; Gordon et al., 2021). For example, the N4-hydroxyl cytosine of molnupiravir was structurally captured to direct the incorporation of either a GMP or an AMP in SARS-CoV-2 RdRP (Kabinger et al., 2021). Unlike immediate chain-terminating NAs or RDV, these mutagenic NAs likely generate antiviral effects by driving the viral population beyond the error-catastrophe threshold.

To date, structures of RdRP-RNA complexes containing noncognate NTP-derived mismatches are rarely reported, while related structures depicting intervention mechanisms of representative NAs have been emerging with the fast growing of RNA virus research (Ferrer-Orta et al., 2007; Appleby et al., 2015; Wang et al., 2020b; Kabinger et al., 2021; Kokic et al., 2021). NAs with immediate chain terminating features may directly interfere with the NAC at the +1 or -1 site (Figure 1Aa-d,Bm-n); those are not immediately terminating can possibly propagate its impact on NAC from remote sites (Figure 1Bo,p); incorporated NAs that eventually become part of the full-length product may affect NAC when reaching the active site and the templateproduct binding regions as a template nucleotide (Figure 1Bq-t). Together with enzymology characterizations, solving more NA-containing RdRP-RNA structures with representative modifications and intervention mechanisms will provide key references for cell- and animal model-based NA effectiveness assessment and a comprehensive pre-clinical evaluation of NA drug candidates.

\section{DISCUSSION}

Representative NAC-related RdRP-RNA complex structures have been reported in picornaviruses, $\mathrm{HCV}$, influenza viruses, bacteriophage $\phi 6$, and more recently in bunyaviruses and CoVs (Butcher et al., 2001; Gong and Peersen, 2010; Gong et al., 2013; Appleby et al., 2015; Arragain et al., 2020; Wang et al., 2020b; Wandzik et al., 2020). However, a comprehensive structural understanding of NAC requires much more representative

\section{REFERENCES}

Abdelkareem, M. m., Saint-André, C., Takacs, M., Papai, G., Crucifix, C., Guo, X., et al. (2019). Structural Basis of Transcription: RNA Polymerase Backtracking and its Reactivation. Mol. Cel. 75, 298-309. doi:10.1016/j.molcel.2019.04.029

Agostini, M. L., Andres, E. L., Sims, A. C., Graham, R. L., Sheahan, T. P., Lu, X., et al. (2018). Coronavirus Susceptibility to the Antiviral Remdesivir (GS-5734) Is Mediated by the Viral Polymerase and the Proofreading Exoribonuclease. mBio 9. doi:10.1128/mBio.00221-18

Appleby, T. C., Perry, J. K., Murakami, E., Barauskas, O., Feng, J., Cho, A., et al. (2015). Structural Basis for RNA Replication by the Hepatitis C Virus Polymerase. Science 347, 771-775. doi:10.1126/science.1259210

Arragain, B., Effantin, G., Gerlach, P., Reguera, J., Schoehn, G., Cusack, S., et al. (2020). Pre-initiation and Elongation Structures of Full-Length La Crosse Virus Polymerase Reveal Functionally Important Conformational Changes. Nat. Commun. 11, 3590. doi:10.1038/s41467-020-17349-4

Bollati, M., Alvarez, K., Assenberg, R., Baronti, C., Canard, B., Cook, S., et al. (2010). Structure and Functionality in Flavivirus NS-Proteins: Perspectives for Drug Design. Antivir. Res. 87, 125-148. doi:10.1016/j.antiviral.2009.11.009

Bradley, C. C., Gordon, A. J. E., Halliday, J. A., and Herman, C. (2019). Transcription Fidelity: New Paradigms in Epigenetic Inheritance, Genome
RdRP systems and determination of RdRP structures at different phases of its replication and transcription. In most cases, the replication/transcription complex (RTC) works as a multi-subunit machinery and its components vary in different processes and at different stages of a certain process (Reed and Rice, 2000; Bollati et al., 2010; Smith and Denison, 2013). Therefore, structures building on RdRP-RNA complex with other RTC components in the assembly are also highly valuable and in some cases more functionally relevant. Continuing progress in cryo electron microscopy (cryo-EM)related techniques and deep learning-based structure prediction of biological macromolecule and its complexes have been providing a boost in understanding the RTC as well as the NAC carried out by it (Frank, 2018; Tunyasuvunakool et al., 2021).

\section{DATA AVAILABILITY STATEMENT}

The original contributions presented in the study are included in the article/supplementary material, further inquiries can be directed to the corresponding author.

\section{AUTHOR CONTRIBUTIONS}

PG surveyed the literature and wrote the manuscript.

\section{FUNDING}

National Key Research and Development Program of China (2018YFA0507200); National Natural Science Foundation of China (32070185); Advanced Customer Cultivation Project of Wuhan National Biosafety Laboratory, Chinese Academy of Sciences (2021ACCP-MS10); Key Biosafety Science and Technology Program of Hubei Jiangxia Laboratory (JXBS001).

Instability and Disease. DNA Repair 81, 102652. doi:10.1016/ j.dnarep.2019.102652

Butcher, S. J., Grimes, J. M., Makeyev, E. V., Bamford, D. H., and Stuart, D. I. (2001). A Mechanism for Initiating RNA-dependent RNA Polymerization. Nature 410, 235-240. doi:10.1038/35065653

Chen, J., Malone, B., Llewellyn, E., Grasso, M., Shelton, P. M. M., Olinares, P. D. B., et al. (2020). Structural Basis for Helicase-Polymerase Coupling in the SARSCoV-2 Replication-Transcription Complex. Cell 182, 1560-1573. doi:10.1016/ j.cell.2020.07.033

Chen, X., Zuo, S., Kelman, Z., O’Donnell, M., Hurwitz, J., and Goodman, M. F. (2000). Fidelity of Eucaryotic DNA Polymerase $\delta$ Holoenzyme fromSchizosaccharomyces Pombe. J. Biol. Chem. 275, 17677-17682. doi:10.1074/jbc.m910278199

Cho, A., Saunders, O. L., Butler, T., Zhang, L., Xu, J., Vela, J. E., et al. (2012). Synthesis and Antiviral Activity of a Series of $1^{\prime}$-substituted 4-Aza-7,9Dideazaadenosine C-Nucleosides. Bioorg. Med. Chem. Lett. 22, 2705-2707. doi:10.1016/j.bmcl.2012.02.105

Crotty, S., Cameron, C. E., and Andino, R. (2001). RNA Virus Error Catastrophe: Direct Molecular Test by Using Ribavirin. Proc. Natl. Acad. Sci. 98, 6895-6900. doi:10.1073/pnas.111085598

Crotty, S., Maag, D., Arnold, J. J., Zhong, W., Lau, J. Y. N., Hong, Z., et al. (2000). The Broad-Spectrum Antiviral Ribonucleoside Ribavirin Is an RNA Virus Mutagen. Nat. Med. 6, 1375-1379. doi:10.1038/82191 
Deaconescu, A. M., Chambers, A. L., Smith, A. J., Nickels, B. E., Hochschild, A., Savery, N. J., et al. (2006). Structural Basis for Bacterial Transcription-Coupled DNA Repair. Cell 124, 507-520. doi:10.1016/j.cell.2005.11.045

Drake, J. W., and Holland, J. J. (1999). Mutation Rates Among RNA Viruses. Proc. Natl. Acad. Sci. 96, 13910-13913. doi:10.1073/pnas.96.24.13910

Feng, J. Y., and Ray, A. S. (2021). HCV RdRp, Sofosbuvir and beyond. The Enzymes 49, 63-82. doi:10.1016/bs.enz.2021.06.003

Ferrer-Orta, C., Arias, A., Perez-Luque, R., Escarmis, C., Domingo, E., and Verdaguer, N. (2007). Sequential Structures Provide Insights into the Fidelity of RNA Replication. Proc. Natl. Acad. Sci. 104, 9463-9468. doi:10.1073/pnas.0700518104

Frank, J. (2018). Single-Particle Reconstruction of Biological Molecules-Story in a Sample (Nobel Lecture). Angew. Chem. Int. Ed. 57, 10826-10841. doi:10.1002/ anie. 201802770

Furuta, Y., Gowen, B. B., Takahashi, K., Shiraki, K., Smee, D. F., and Barnard, D. L. (2013). Favipiravir (T-705), a Novel Viral RNA Polymerase Inhibitor. Antivir. Res. 100, 446-454. doi:10.1016/j.antiviral.2013.09.015

Gane, E. J., Stedman, C. A., Hyland, R. H., Ding, X., Svarovskaia, E., Symonds, W. T., et al. (2013). Nucleotide Polymerase Inhibitor Sofosbuvir Plus Ribavirin for Hepatitis C. N. Engl. J. Med. 368, 34-44. doi:10.1056/nejmoa1208953

Gong, P., Kortus, M. G., Nix, J. C., Davis, R. E., and Peersen, O. B. (2013). Structures of Coxsackievirus, Rhinovirus, and Poliovirus Polymerase Elongation Complexes Solved by Engineering RNA Mediated crystal Contacts. PloS one 8, e60272. doi:10.1371/journal.pone.0060272

Gong, P., and Peersen, O. B. (2010). Structural Basis for Active Site Closure by the Poliovirus RNA-dependent RNA Polymerase. Proc. Natl. Acad. Sci. 107, 22505-22510. doi:10.1073/pnas.1007626107

Gong, P. (2021). Structural Basis of Viral RNA-dependent RNA Polymerase Nucleotide Addition Cycle in Picornaviruses. The Enzymes 49, 215-233. doi:10.1016/bs.enz.2021.06.002

Gordon, C. J., Tchesnokov, E. P., Feng, J. Y., Porter, D. P., and Götte, M. (2020). The Antiviral Compound Remdesivir Potently Inhibits RNA-dependent RNA Polymerase from Middle East Respiratory Syndrome Coronavirus. J. Biol. Chem. 295, 4773-4779. doi:10.1074/jbc.ac120.013056

Gordon, C. J., Tchesnokov, E. P., Schinazi, R. F., and Götte, M. (2021). Molnupiravir Promotes SARS-CoV-2 Mutagenesis via the RNA Template. J. Biol. Chem. 297, 100770. doi:10.1016/j.jbc.2021.100770

Gordon, C. J., Tchesnokov, E. P., Woolner, E., Perry, J. K., Feng, J. Y., Porter, D. P., et al. (2020). Remdesivir Is a Direct-Acting Antiviral that Inhibits RNAdependent RNA Polymerase from Severe Acute Respiratory Syndrome Coronavirus 2 with High Potency. J. Biol. Chem. 295, 6785-6797. doi:10.1074/jbc.ra120.013679

Guajardo, R., and Sousa, R. (1997). A Model for the Mechanism of Polymerase Translocation 1 1Edited by A. R. Fersht. J. Mol. Biol. 265, 8-19. doi:10.1006/ jmbi.1996.0707

Guo, X., Myasnikov, A. G., Chen, J., Crucifix, C., Papai, G., Takacs, M., et al. (2018). Structural Basis for NusA Stabilized Transcriptional Pausing. Mol. Cel. 69, 816-827. doi:10.1016/j.molcel.2018.02.008

Huang, H., Chopra, R., Verdine, G. L., and Harrison, S. C. (1998). Structure of a Covalently Trapped Catalytic Complex of HIV-1 Reverse Transcriptase: Implications for Drug Resistance. Science 282, 1669-1675. doi:10.1126/ science.282.5394.1669

Imashimizu, M., Kireeva, M. L., Lubkowska, L., Kashlev, M., and Shimamoto, N. (2019). The Role of Pyrophosphorolysis in the Initiation-To-Elongation Transition by E. coli RNA Polymerase. J. Mol. Biol. 431, 2528-2542. doi:10.1016/j.jmb.2019.04.020

Jacobs, M., Rodger, A., Bell, D. J., Bhagani, S., Cropley, I., Filipe, A., et al. (2016). Late Ebola Virus Relapse Causing Meningoencephalitis: a Case Report. The Lancet 388, 498-503. doi:10.1016/s0140-6736(16)30386-5

Jia, H., and Gong, P. (2019). A Structure-Function Diversity Survey of the RNAdependent RNA Polymerases from the Positive-Strand RNA Viruses. Front. Microbiol. 10, 1945. doi:10.3389/fmicb.2019.01945

Jia, X., Ganter, B., and Meier, C. (2021). Improving Properties of the Nucleobase Analogs T-705/T-1105 as Potential Antiviral. Annu. Rep. Med. Chem. 57, 1-47. doi:10.1016/bs.armc.2021.08.002

Jin, Z., Leveque, V., Ma, H., Johnson, K. A., and Klumpp, K. (2013). NTP-mediated Nucleotide Excision Activity of Hepatitis C Virus RNA-dependent RNA
Polymerase. Proc. Natl. Acad. Sci. 110, E348-E357. doi:10.1073/ pnas. 1214924110

Jin, Z., Smith, L. K., Rajwanshi, V. K., Kim, B., and Deval, J. (2013). The Ambiguous Base-Pairing and High Substrate Efficiency of T-705 (Favipiravir) Ribofuranosyl 5'-Triphosphate towards Influenza A Virus Polymerase. PloS one 8, e68347. doi:10.1371/journal.pone.0068347

Johnson, K. A., and Dangerfield, T. (2021). Mechanisms of Inhibition of Viral RNA Replication by Nucleotide Analogs. The Enzymes 49, 39-62. doi:10.1016/ bs.enz.2021.07.001

Johnson, R. E., Prakash, S., and Prakash, L. (2000). The Human DINB1 Gene Encodes the DNA Polymerase Poltheta. Proc. Natl. Acad. Sci. 97, 3838-3843. doi:10.1073/pnas.97.8.3838

Johnson, S. J., and Beese, L. S. (2004). Structures of Mismatch Replication Errors Observed in a DNA Polymerase. Cell 116, 803-816. doi:10.1016/s00928674(04)00252-1

Kabinger, F., Stiller, C., Schmitzová, J., Dienemann, C., Kokic, G., Hillen, H. S., et al. (2021). Mechanism of Molnupiravir-Induced SARS-CoV-2 Mutagenesis. Nat. Struct. Mol. Biol. 28, 740-746. doi:10.1038/s41594-021-00651-0

Kang, J. Y., Mishanina, T. V., Bellecourt, M. J., Mooney, R. A., Darst, S. A., and Landick, R. (2018). RNA Polymerase Accommodates a Pause RNA Hairpin by Global Conformational Rearrangements that Prolong Pausing. Mol. Cel. 69, 802-815. doi:10.1016/j.molcel.2018.01.018

Kassavetis, G. A., and Chamberlin, M. J. (1981). Pausing and Termination of Transcription within the Early Region of Bacteriophage T7 DNA In Vitro. J. Biol. Chem. 256, 2777-2786. doi:10.1016/s0021-9258(19)69682-1

Kidmose, R. T., Vasiliev, N. N., Chetverin, A. B., Andersen, G. R., and Knudsen, C. R. (2010). Structure of the Q Replicase, an RNA-dependent RNA Polymerase Consisting of Viral and Host Proteins. Proc. Natl. Acad. Sci. 107, 10884-10889. doi:10.1073/pnas.1003015107

Kirchdoerfer, R. N., and Ward, A. B. (2019). Structure of the SARS-CoV Nsp12 Polymerase Bound to Nsp7 and Nsp8 Co-factors. Nat. Commun. 10, 2342. doi:10.1038/s41467-019-10280-3

Kokic, G., Hillen, H. S., Tegunov, D., Dienemann, C., Seitz, F., Schmitzova, J., et al. (2021). Mechanism of SARS-CoV-2 Polymerase Stalling by Remdesivir. Nat. Commun. 12, 279. doi:10.1038/s41467-020-20542-0

Kornberg, R. D. (2007). The Molecular Basis of Eukaryotic Transcription. Proc. Natl. Acad. Sci. 104, 12955-12961. doi:10.1073/pnas.0704138104

Krupovic, M., Cvirkaite-Krupovic, V., Iranzo, J., Prangishvili, D., and Koonin, E. V. (2018). Viruses of Archaea: Structural, Functional, Environmental and Evolutionary Genomics. Virus. Res. 244, 181-193. doi:10.1016/ j.virusres.2017.11.025

Lesburg, C. A., Cable, M. B., Ferrari, E., Hong, Z., Mannarino, A. F., and Weber, P. C. (1999). Crystal Structure of the RNA-dependent RNA Polymerase from Hepatitis C Virus Reveals a Fully Encircled Active Site. Nat. Struct. Biol. 6, 937-943. doi:10.1038/13305

Li, Y., Korolev, S., and Waksman, G. (1998). Crystal Structures of Open and Closed Forms of Binary and Ternary Complexes of the Large Fragment of Thermus Aquaticus DNA Polymerase I: Structural Basis for Nucleotide Incorporation. EMBO J. 17, 7514-7525. doi:10.1093/emboj/17.24.7514

Liang, B., Li, Z., Jenni, S., Rahmeh, A. A., Morin, B. M., Grant, T., et al. (2015). Structure of the L Protein of Vesicular Stomatitis Virus from Electron Cryomicroscopy. Cell 162, 314-327. doi:10.1016/j.cell.2015.06.018

Liu, W., Shi, X., and Gong, P. (2018). A Unique Intra-molecular FidelityModulating Mechanism Identified in a Viral RNA-dependent RNA Polymerase. Nucleic Acids Res. 46, 10840-10854. doi:10.1093/nar/gky848

Lu, G., and Gong, P. (2013). Crystal Structure of the Full-Length Japanese Encephalitis Virus NS5 Reveals a Conserved Methyltransferase-Polymerase Interface. Plos Pathog. 9, e1003549. doi:10.1371/journal.ppat.1003549

Macdonald, L. E., Durbin, R. K., Dunn, J. J., and McAllister, W. T. (1994). Characterization of Two Types of Termination Signal for Bacteriophage T7 RNA Polymerase. J. Mol. Biol. 238, 145-158. doi:10.1006/jmbi.1994.1277

Malone, B., Chen, J., Wang, Q., Llewellyn, E., Choi, Y. J., Olinares, P. D. B., et al. (2021). Structural Basis for Backtracking by the SARS-CoV-2 ReplicationTranscription Complex. Proc. Natl. Acad. Sci. United States America 118. doi:10.1073/pnas.2102516118

Meyer, P. R., Matsuura, S. E., So, A. G., and Scott, W. A. (1998). Unblocking of Chain-Terminated Primer by HIV-1 Reverse Transcriptase through a 
Nucleotide-dependent Mechanism. Proc. Natl. Acad. Sci. 95, 13471-13476. doi:10.1073/pnas.95.23.13471

Murphy, M. N., Gong, P., Ralto, K., Manelyte, L., Savery, N. J., and Theis, K. (2009). An N-Terminal Clamp Restrains the Motor Domains of the Bacterial Transcription-Repair Coupling Factor Mfd. Nucleic Acids Res. 37, 6042-6053. doi:10.1093/nar/gkp680

Peersen, O. B. (2017). Picornaviral Polymerase Structure, Function, and Fidelity Modulation. Virus. Res. 234, 4-20. doi:10.1016/j.virusres.2017.01.026

Pflug, A., Guilligay, D., Reich, S., and Cusack, S. (2014). Structure of Influenza A Polymerase Bound to the Viral RNA Promoter. Nature 516, 355-360. doi:10.1038/nature14008

Reed, K. E., and Rice, C. M. (2000). Overview of Hepatitis C Virus Genome Structure, Polyprotein Processing, and Protein Properties. Curr. Top. Microbiol. Immunol. 242, 55-84. doi:10.1007/978-3-642-59605-6_4

Reich, S., Guilligay, D., Pflug, A., Malet, H., Berger, I., Crépin, T., et al. (2014). Structural Insight into Cap-Snatching and RNA Synthesis by Influenza Polymerase. Nature 516, 361-366. doi:10.1038/nature14009

Roberts, J. W. (2019). Mechanisms of Bacterial Transcription Termination. J. Mol. Biol. 431, 4030-4039. doi:10.1016/j.jmb.2019.04.003

Rubin, D., Chan-Tack, K., Farley, J., and Sherwat, A. (2020). FDA Approval of Remdesivir - A Step in the Right Direction. N. Engl. J. Med. 383, 2598-2600. doi:10.1056/nejmp2032369

Seifert, M., Bera, S. C., van Nies, P., Kirchdoerfer, R. N., Shannon, A., Le, T. T., et al. (2021). Inhibition of SARS-CoV-2 Polymerase by Nucleotide Analogs from a Single-Molecule Perspective. eLife 10. doi:10.7554/eLife.70968

Seley-Radtke, K. L., Thames, J. E., and Waters, C. D., 3rd. (2021). Broad Spectrum Antiviral Nucleosides-Our Best hope for the Future. Annu. Rep. Med. Chem. 57, 109-132. doi:10.1016/bs.armc.2021.09.001

Shu, B., and Gong, P. (2016). Structural Basis of Viral RNA-dependent RNA Polymerase Catalysis and Translocation. Proc. Natl. Acad. Sci. USA 113, E4005-E4014. doi:10.1073/pnas.1602591113

Smith, E. C., and Denison, M. R. (2013). Coronaviruses as DNA Wannabes: a New Model for the Regulation of RNA Virus Replication Fidelity. Plos Pathog. 9, e1003760. doi:10.1371/journal.ppat.1003760

Steitz, T. A., and Steitz, J. A. (1993). A General Two-Metal-Ion Mechanism for Catalytic RNA. Proc. Natl. Acad. Sci. 90, 6498-6502. doi:10.1073/pnas.90.14.6498

Subissi, L., Posthuma, C. C., Collet, A., Zevenhoven-Dobbe, J. C., Gorbalenya, A. E., Decroly, E., et al. (2014). One Severe Acute Respiratory Syndrome Coronavirus Protein Complex Integrates Processive RNA Polymerase and Exonuclease Activities. Proc. Natl. Acad. Sci. USA 111, E3900-E3909. doi:10.1073/ pnas. 1323705111

Tchesnokov, E. P., Gordon, C. J., Woolner, E., Kocinkova, D., Perry, J. K., Feng, J. Y., et al. (2020). Template-dependent Inhibition of Coronavirus RNAdependent RNA Polymerase by Remdesivir Reveals a Second Mechanism of Action. J. Biol. Chem. 295, 16156-16165. doi:10.1074/jbc.ac120.015720

Temiakov, D., Patlan, V., Anikin, M., McAllister, W. T., Yokoyama, S., and Vassylyev, D. G. (2004). Structural Basis for Substrate Selection by T7 RNA Polymerase. Cell 116, 381-391. doi:10.1016/s0092-8674(04)00059-5

Thompson, A. A., and Peersen, O. B. (2004). Structural Basis for Proteolysisdependent Activation of the Poliovirus RNA-dependent RNA Polymerase. Embo J. 23, 3462-3471. doi:10.1038/sj.emboj.7600357

Tunyasuvunakool, K., Adler, J., Wu, Z., Green, T., Zielinski, M., Žídek, A., et al. (2021). Highly Accurate Protein Structure Prediction for the Human Proteome. Nature 596, 590-596. doi:10.1038/s41586-021-03828-1

Vassylyev, D. G., and Artsimovitch, I. (2005). Tracking RNA Polymerase, One Step at a Time. Cell 123, 977-979. doi:10.1016/j.cell.2005.11.030

Wandzik, J. M., Kouba, T., Karuppasamy, M., Pflug, A., Drncova, P., Provaznik, J., et al. (2020). A Structure-Based Model for the Complete Transcription Cycle of Influenza Polymerase. Cell 181, 877-893. doi:10.1016/j.cell.2020.03.061

Wang, D., Bushnell, D. A., Huang, X., Westover, K. D., Levitt, M., and Kornberg, R. D. (2009). Structural Basis of Transcription: Backtracked RNA Polymerase II at 3.4 Angstrom Resolution. Science 324, 1203-1206. doi:10.1126/science.1168729

Wang, D., Bushnell, D. A., Westover, K. D., Kaplan, C. D., and Kornberg, R. D. (2006). Structural Basis of Transcription: Role of the Trigger Loop in Substrate Specificity and Catalysis. Cell 127, 941-954. doi:10.1016/j.cell.2006.11.023
Wang, M., Li, R., Shu, B., Jing, X., Ye, H.-Q., and Gong, P. (2020). Stringent Control of the RNA-dependent RNA Polymerase Translocation Revealed by Multiple Intermediate Structures. Nat. Commun. 11, 2605. doi:10.1038/s41467-02016234-4

Wang, Q., Wu, J., Wang, H., Gao, Y., Liu, Q., Mu, A., et al. (2020). Structural Basis for RNA Replication by the SARS-CoV-2 Polymerase. Cell 182, 417-428. doi:10.1016/j.cell.2020.05.034

Wolf, Y. I., Kazlauskas, D., Iranzo, J., Lucía-Sanz, A., Kuhn, J. H., Krupovic, M., et al. (2018). Origins and Evolution of the Global RNA Virome. mBio 9 (6), e02329-18. doi:10.1128/mBio.02329-18

Wu, J., Wang, H., Liu, Q., Li, R., Gao, Y., Fang, X., et al. (2021). Remdesivir Overcomes the S861 Roadblock in SARS-CoV-2 Polymerase Elongation Complex. Cel Rep. 37, 109882. doi:10.1016/j.celrep.2021.109882

Xu, H. T., Hassounah, S. A., Colby-Germinario, S. P., Oliveira, M., Fogarty, C., Quan, Y., et al. (2017). Purification of Zika Virus RNA-dependent RNA Polymerase and its Use to Identify Small-Molecule Zika Inhibitors. J. Antimicrob. Chemother. 72, 727-734. doi:10.1093/jac/dkw514

Yan, L., Ge, J., Zheng, L., Zhang, Y., Gao, Y., Wang, T., et al. (2021). Cryo-EM Structure of an Extended SARS-CoV-2 Replication and Transcription Complex Reveals an Intermediate State in Cap Synthesis. Cell 184, 184-193. doi:10.1016/ j.cell.2020.11.016

Yan, L., Yang, Y., Li, M., Zhang, Y., Zheng, L., Ge, J., et al. (2021). Coupling of N7Methyltransferase and $3^{\prime}-5^{\prime}$ Exoribonuclease with SARS-CoV-2 Polymerase Reveals Mechanisms for Capping and Proofreading. Cell 184, 3474-3485. doi:10.1016/j.cell.2021.05.033

Yarnell, W. S., and Roberts, J. W. (1999). Mechanism of Intrinsic Transcription Termination and Antitermination. Science 284, 611-615. doi:10.1126/ science.284.5414.611

Yin, Y. W., and Steitz, T. A. (2004). The Structural Mechanism of Translocation and Helicase Activity in T7 RNA Polymerase. Cell 116, 393-404. doi:10.1016/ s0092-8674(04)00120-5

Zamyatkin, D. F., Parra, F., Alonso, J. M. M., Harki, D. A., Peterson, B. R., Grochulski, P., et al. (2008). Structural Insights into Mechanisms of Catalysis and Inhibition in Norwalk Virus Polymerase. J. Biol. Chem. 283, 7705-7712. doi:10.1074/jbc.m709563200

Zhang, B.-Y., Liu, W., Jia, H., Lu, G., and Gong, P. (2021). An Induced-Fit De Novo Initiation Mechanism Suggested by a Pestivirus RNA-dependent RNA Polymerase. Nucleic Acids Res. 49, 8811-8821. doi:10.1093/nar/gkab666

Zhang, Y., Yuan, F., Xin, H., Wu, X., Rajpal, D. K., Yang, D., et al. (2000). Human DNA Polymerase Kappa Synthesizes DNA with Extraordinarily Low Fidelity. Nucleic Acids Res. 28, 4147-4156. doi:10.1093/nar/28.21.4147

Zhou, P., Yang, X.-L., Wang, X.-G., Hu, B., Zhang, L., Zhang, W., et al. (2020). A Pneumonia Outbreak Associated with a New Coronavirus of Probable Bat Origin. Nature 579, 270-273. doi:10.1038/s41586-020-2012-7

Zhou, Y., Navaroli, D. M., Enuameh, M. S., and Martin, C. T. (2007). Dissociation of Halted T7 RNA Polymerase Elongation Complexes Proceeds via a ForwardTranslocation Mechanism. Proc. Natl. Acad. Sci. 104, 10352-10357. doi:10.1073/pnas.0606306104

Conflict of Interest: The author declares that the research was conducted in the absence of any commercial or financial relationships that could be construed as a potential conflict of interest.

Publisher's Note: All claims expressed in this article are solely those of the authors and do not necessarily represent those of their affiliated organizations, or those of the publisher, the editors and the reviewers. Any product that may be evaluated in this article, or claim that may be made by its manufacturer, is not guaranteed or endorsed by the publisher.

Copyright $\odot 2022$ Gong. This is an open-access article distributed under the terms of the Creative Commons Attribution License (CC BY). The use, distribution or reproduction in other forums is permitted, provided the original author(s) and the copyright owner(s) are credited and that the original publication in this journal is cited, in accordance with accepted academic practice. No use, distribution or reproduction is permitted which does not comply with these terms. 